Portland State University

PDXScholar

1985

\title{
The MMPI : a subscale (Ic) for the identification of male incest offenders
}

Mary S. Dolan

Portland State University

Follow this and additional works at: https://pdxscholar.library.pdx.edu/open_access_etds

Part of the Criminology and Criminal Justice Commons, and the Psychology Commons Let us know how access to this document benefits you.

\section{Recommended Citation}

Dolan, Mary S., "The MMPI : a subscale (Ic) for the identification of male incest offenders" (1985). Dissertations and Theses. Paper 3406.

https://doi.org/10.15760/etd.5289

This Thesis is brought to you for free and open access. It has been accepted for inclusion in Dissertations and Theses by an authorized administrator of PDXScholar. Please contact us if we can make this document more accessible: pdxscholar@pdx.edu. 
AN ABSTRACT OF THE THESIS OF MARY S. DOLAN for the Master of Science in Psychology presented February 27, 1985.

Title: The MMPI: A Subscale (Ic) for the Identification of Male Incest offenders

APPROVED BY MEMBERS OF THE THESIS COMMITTEE:

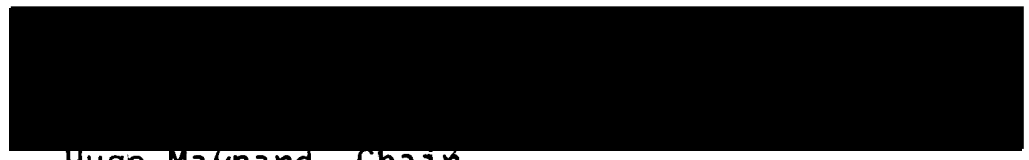

Hugo Maynard, Cha ir

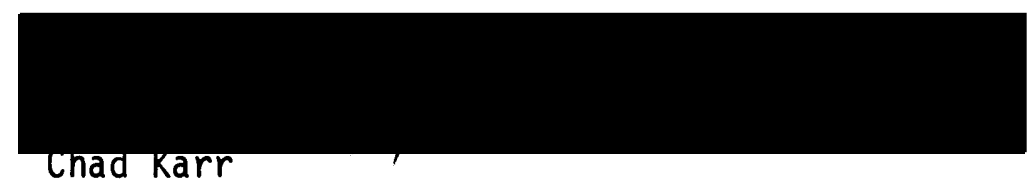

Chad Karr

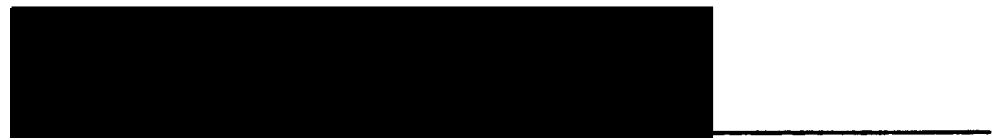

Peter Barbur

The MMPI has been used extensively for the clinical assessment of deviancy among sexual offenders. In order to derive a diagnostic scale for the specific identification of male incest offenders, an item analysis, using MMPI data from offenders, compared MMPI data from a nonoffending control sample. The item analys is results were cross validated with MMPI data from a separate sample of incest offenders. Eleven MMPI items were found to be critical in discriminating male incest offenders from nonoffenders, and these items comprise the IC experimental scale. On the basis of the Ic scale, male incest offenders 
evidence characterological disturbances in the form of pervasive feelings of psychological and social inadequacy. 
TO THE OFFICE OF GRADUATE STUDIES AND RESEARCH:

The members of the Committee approve the thesis of Mary S. Dolan presented February 27, 1985.

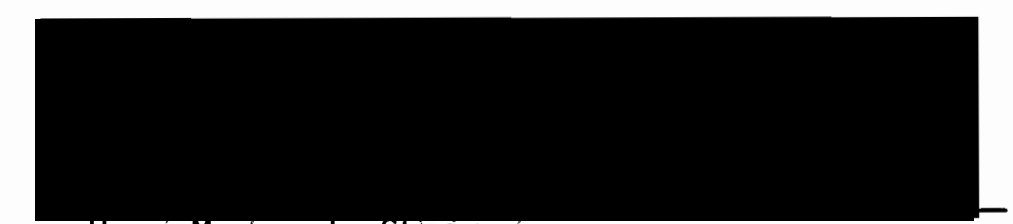

Huga Maynard, Chajr

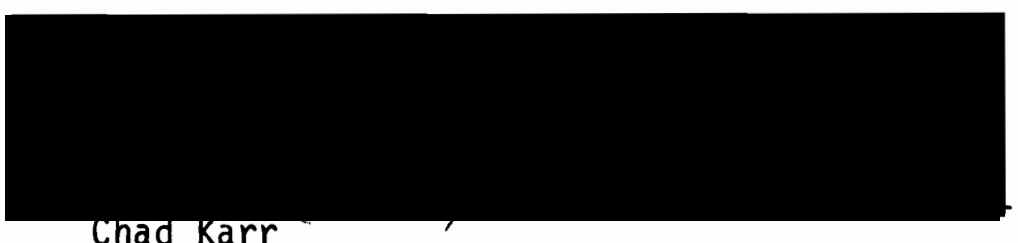

Chad Karr

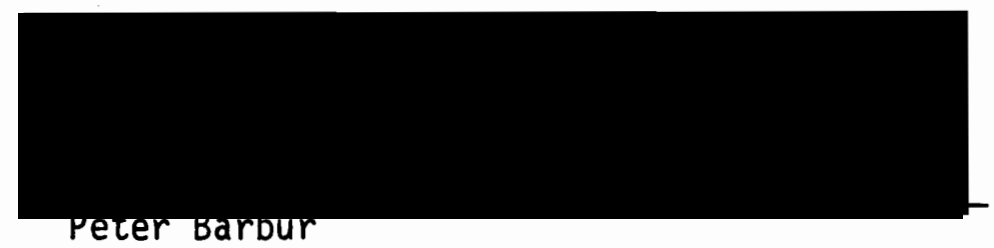

APPROVED:

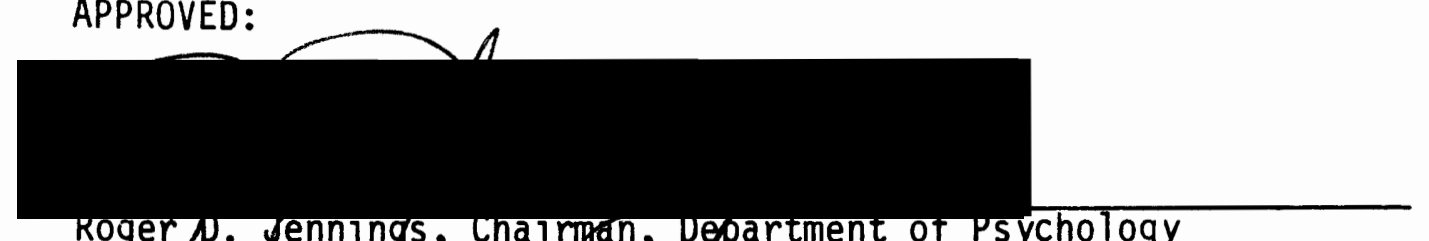

Roger J. sennings, cha irman, Uepartment of Psychology 


\section{ACKNOWLEDGMENTS}

I am indebted to Toni Farrenkopf, Ph.D., for his generosity in allowing me access to his clinical files on incest offenders; to Robert Kopp, for his competence in performing the computerized statistical analyses; to Linda Ladd, for reference sources, and for permitting me the use of her MMPI data that formed the control sample; and to Sally Lopez, for her expert typing services. In particular, I owe an enormous debt to two special individuals: To Peter, for the original idea of the present study, for his support and good-natured prodding, and especially for his laughter--to be repaid with interest. And to Terry, who never gave up hope, who never lost confidence in me, and who has always been supportive and encouraging. Thank you. 
TABLE OF CONTENTS

PAGE

ACKNOWLEDGMENTS . . . . . . . . . . . . . . . .

LIST OF TABLES . . . . . . . . . . . . . . •

LIST OF FIGURES . . . . . . . . . . . . . . .

CHAPTER

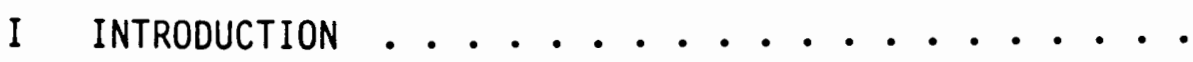

MMPI Assessment of Sexual Offenders .....

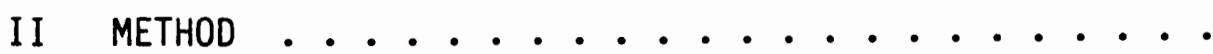

Subjects ............... . .

Materials ...............

Scale Development Methodology .......

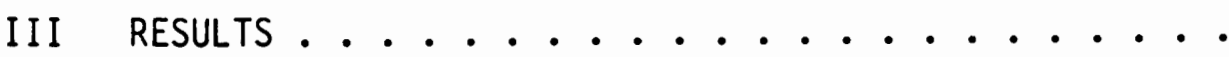

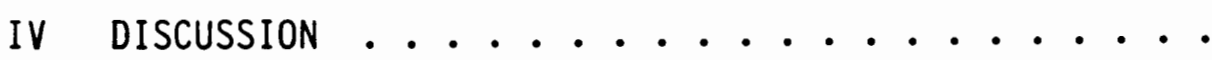

REFERENCES ....................... 


\section{LIST OF TABLES}

TABLE

I Percent of Correctly and Incorrectly Classified

Subjects for the 15- and 11-Item Incest

Offender Scale (Ic) . . . . . . . . .

II Incest offender Scale (IC) . . . . . . . . 26

III MMPI Scale Descriptors . . . . . . . . . . 44

IV MMPI Question Booklet Items Used by Group 1 Criterion

Offenders and Corresponding Item Number Used by

Group 2 Controls ............

$\checkmark$ Original Critical Items Omitted in the Development of

the (IC) MMPI Scale . . . . . . . . .

VI Standardized Canonical Discriminant Coefficients Applied

to the 15-Item MMPI Experimental Incest offender

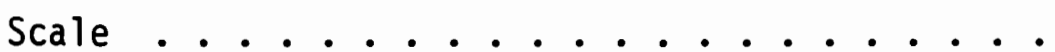

VII Standardized Canonical Discriminant Coefficients Applied to MMPI Validity and Clinical Scale Scores .... 


\section{LIST OF FIGURES}

FIGURE

PAGE

1. Response Rate on the 15-Item MMPI Experimental Incest

Offender Scale With an Arbitrary Cutting Score

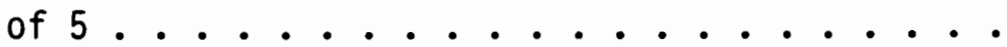

2. Response Rate on the 11-Item MMPI Experimental Incest Offender Scale With an Arbitrary Cutting Score

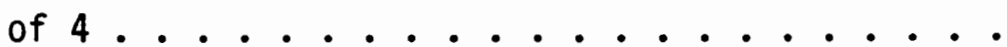

3. Group 1, Criterion Offender Sample $(\underline{n}=66)$, Means and Standard Deviations for K-Corrected MMPI Scale Scores ...............

4. Group 2, Control Sample $(\underline{n}=37)$, Means and

Standard Deviations for $\underline{K}$-Corrected MMPI Scale Scores................

5. Group 3, Experimental Offender Sample $(\underline{n}=33)$, Means and Standard Deviations for $\underline{K}$-Corrected MMPI Scale Scores ................. 


\section{CHAPTER I}

\section{INTRODUCTION}

Incest is the practice of sexual relations with blood relatives or kin, including one's own children. The pervasiveness of incest and its long-term psychological impact for families and victims have recently gained attention, particularly in the popular press (Bass \& Thornton, 1983; Harris, 1984; Kempe \& Kempe, 1984; Rush, 1980; Watson, Lubenow, Greenberg, King, \& Junkin, 1984). By its very nature, incest-especially between parent and child--is an emotionally laden and socially unacceptable form of sexual abuse.

The practice of incest is a universal taboo (Herman \& Hirschman, 1981; Sarles, 1975). In describing kinship structures, Levi-Strauss (1969, p. 481) considered the incest taboo to be "the fundamental and immutable rule" that provides the foundation for the existence of all social groups. Freud $(1913 / 1946$, p. 13) regarded the taboo as the "basis for all other social obligations and moral restrictions" within a cultural system. The formulation of the incest taboo has been explained, in part, as deriving from an inherent biological prohibition against inbreeding (Lindzey, 1967), as a social measure to insure the integrity, cohesiveness, and solidarity of the family unit (Lester, 1972), and as a mechanism to eliminate role strain, confusion, and rivalry among family members (DeVine, 1980).

Statistics on the incidence of incest reflect only those cases 
reported to appropriate authorities or agencies. The actual occurrence of incest is difficult to establish. The National Center on Child Abuse and Neglect (1981) estimates that over 100,000 children are sexually abused in the United States each year. A recent survey focusing on the sexual exploitation of women reported that, of the women sampled, $38 \%$ had experienced unwanted sexual approach before age 18 (Russe11, 1984). Within Oregon, the Children's Services Division (Protective Services, 1984) documented over 1500 incidents of child sexual molestation during 1983, constituting a 1700\% increase in reported cases since 1975 . Reporting of incest remains low, however, reflecting the preeminence of the incest taboo, fear of family disruptions, and fear of societal reactions, as well as guilt of the participants.

A variety of theoretical explanations for incest have been advanced. In psychoanalytic theory, the essential feature of psychosexual development is the resolution of the Oedipal complex--the redirection of incestuous impulses toward the opposite-sexed parent to form an identification with the same-sexed parent (Freud, 1940/1949). In accordance with Freud (1940/1949), Cavallin (1966) proposed a psychodynamic model for incest, postulating that incestuous acts result from displaced positive Oedipal strivings as well as hostility in offenders toward their mothers that is recreated in their present relationships with their wives and daughters. Such strivings and hostilities culminate in the expression of serious pregenital and genital conflicts as represented by actual incestuous acts. In addition, Cavallin suggested that the presence of the child causes the 
offender to reexperience "forbidden gratifications" and unconscious "tortuous" early anxieties, and that for the incestuous fathers, interaction with a daughter poses a serious threat to ego organization and may generate a regression of ego defenses.

In contrast to a psychodynamic perspective, Quinsey (1977) proposed that incest represents a "situational offense," and he related incestuous child molesting to family dynamics and opportunism rather than to an inappropriate sexual object choice on the part of the offender.

Weinberg (1955) theorized that incestuous behavior could be classified into three distinct categories: (a) incest as a pattern of sexual psychopathology involving indiscriminate promiscuity, (b) pedophilia arising from social and psychosexual immaturity, and (c) intrafamilial incest resulting from emotional deprivation on behalf of the participants, chaotic early family life, extreme emotional dependence, poor impulse control, and nonaggressive, ineffectual personality attributes.

Hypothesizing that the offender is not the sole responsible party in incestuous situations, Machotka, Pittman, and Flomenhaft (1967) proposed the development of an "interpersonal triangle" within the family, composed of the offender, the victim, and a family member-usually the spouse--who does not overtly participate in the incestuous behavior, but who fosters its continuance by collusion. Machotka et al. (1967) state that "pathological relationships are perpetuated by the nonparticipating member's denial of the incest and the consequent 
'secret' it creates." The theory that collusion on behalf of family members serves as a possible contributory mechanism in sustaining incestuous behavior is further supported by Cormier, Kennedy, and Sangowicz (1962), the National Center on Child Abuse and Neglect (1980), Raphling, Carpenter, and Davis (1967), and Sarles (1975).

In keeping with the hypothesis of Machotka et a1. (1967) regarding family involvement, Anderson and Shafer (1979) viewed the entire family unit as analogous to a "character-disordered" individual, thus establishing a climate in which incest may occur. According to this model, many of the characteristics descriptive of the incestuous parent may also apply to other family members, including the spouse. Anderson and Shafer placed the incestuous "character-disordered" family on a diagnostic continuum with regard to the prevalence of the following characteristics: (a) difficulty with impulse control, including low frustration tolerance and demand for immediate need gratification that is expressed by sexual acting out, or drug or alcohol abuse; (b) poor judgment and inability to learn from experience; (c) a history of conflicts with authority; (d) physical, as opposed to verbal, expression of needs; (e) manipulativeness; (f) irresponsibility; (g) a lack of conscience, as evidenced by minimal expression of guilt over sexual behavior; (h) callousness, relating to people as objects; (i) narcissism, self-indulgent behavior; $(j)$ low anxiety; (k) major conflicts over dependency; and (1) an inability to tolerate intimacy, often masked by a social facade.

Expanding his hypothesis that incestuous behavior represents a 
"situational offense" arising from family dysfunction, Quinsey (1977) postulated that offenders have a relatively low recidivism rate. Cormier et al. (1962) distinguished recidivism rates on the basis of pre- and postdisclosure of the incest relationship. While noting that it is not exceptional for an incestuous parent to continue a relationship over a period of years, often with more than one child, Cormier et al. (1962) stated that once the incest has been acknowledged, repetition of such behavior is rare.

\section{MMPI ASSESSMENT OF SEXUAL OFFENDERS}

Numerous researchers have utilized the Minnesota Multiphasic Personality Inventory (MMPI) as a means of assessing various sex offender populations. The MMPI provides objective, easily administered, and scored information in the areas of attitudes, affect, personality traits, and psychiatric symptomology (Dahlstron \& Welsh, 1960); see Table III, Appendix, for MMPI scale descriptors.

Interpreting MMPI data from incestuous fathers, Cavallin (1966) determined that offenders evidenced: (a) inadequate or weak object relations, (b) poor psychosexual identity, (c) unconscious homosexual tendencies, and (d) projection as their primary defense mechanism.

Other researchers have computed mean MMPI scale elevations in efforts to establish modal profiles that identify the salient characteristics of sex offenders. Anderson and Shafer (1979) found significant elevations on scale 4 (Psychopathic deviate) among incestuous fathers. This finding corroborated an early study by Swenson 
and Grimes (1958), who described first-time sex offenders as rebellious and introverted, in addition to displaying antisocial behaviors.

Panton (1979) compared mean MMPI scale scores and elevations of fathers convicted of incest with those of men incarcerated for the crime of child sexual molestation. Incest offenders were found to have higher elevations on scales 4 (Psychopathic deviate), 2 (Depression), and 0 (Social introversion). An analys is of scale 4 items endorsed by both groups led Panton to conclude that incest offenders generally experienced family disruption during their formative years and social alienation as they grew older. This is in agreement with the previous hypotheses of Anderson and Shafer (1979) and Swenson and Grimes (1958) that offenders lead antisocial lifestyles, engage in acting out, and have conflicts with authority as adults.

Langevin, Paitich, Freeman, Mann, and Handy (1978) found incestuous males to have high mean $T$ scores on scales 2 and 6 (Paranoia), in addition to high scale 4 elevations. Langevin et al. (1978) characterized incestuous fathers, on the basis of MMPI data, as being reserved or introverted and only minimally assertive. In comparison with a control sample, incest offenders were generally found to be less intelligent or intuitive, but more conscientious, shy, conservative, and more guilt prone. It was further determined that incestuous fathers suffered substantial emotional disturbances that may serve as a possible causal element in their inappropriate object choice of children.

In a comparative study of group mean MMPI profiles of adult and child rapists with nonrapist sex offenders, including incestuous 
fathers, Armentrout and Haver (1978) found that the two-point codes of $49 / 94$ and $48 / 84$ were modal for nonrapist sex offenders, findings which were consistent with those of Cabeen and Coleman (1961), McCreary (1975), Panton (1958), Rader (1977), Swenson and Grimes (1958), and Wattron (1958). More significantly, however, Armentrout and Hauer determined that heterogeneity was the characteristic most representative of all three groups of mean MMPI profiles, and that no single two-point code could accurately discriminate among individual sex offenders. Supporting the findings of Armentrout and Hauer (1978), Anderson, Kunce, and Rich (1979) found no significant differences among child molesters, rapists, or incestuous fathers on three dominant MMPI profile types of "ㅌ, $\underline{S c}, "(\underline{F}, 8)$, "Pd, Ma,,$(4,9)$, and "모, $\underline{P d}, "(2,4)$ as determined by a factor analytic technique. Anderson et al. (1979) suggested that the development of specific MMPI profiles for identifying certain crime classifications would prove unsuccessful. Based on their study, Anderson et al. (1979) hypothesized that sex offenders had histories of other criminal activities as well as other problems such as chemical abuse that diluted the predictive strength of the MMPI as an offender classification instrument.

Kirkland and Bauer (1982) compiled mean MMPI profiles for a combined group of five natural fathers and five stepfathers found guilty of incest. Ninety percent of the offenders had pathologically elevated $(T \geq 70)$ two-point codes on the clinical scales. In addition, offenders' mean scores were significantly elevated on scales 4,7 (Psychasthenia), and 8 (Schizophrenia). 
In an early study conducted by Hartman (1967), men diagnosed as sociopathic personalities with associated sexual deviance were compared with men diagnosed as sociopathic with associated antisocial reaction or alcoholism. The MMPI was administered to all subjects, and all profiles had elevated scale 4 scores $(T>70)$. Scores on eleven experimental MMPI scales were then compared in an effort to differentiate the two subject groups. No significant differences between groups were found on the following scales: (a) sexual deviation, (b) amorality, (c) social alienation, (d) impulsivity, (e) hostility, (f) personal and emotional sensitivity, (g) ego strength, (h) control, (i) responsibility, (j) manifest anxiety, and (k) emotional immaturity.

Two experimental MMPI scales have been developed for the identification of sex offenders. The Sexual Deviation scale (Sv) was formulated by Marsh, Hilliard, and Liechti (1955) in an effort to distinguish convicted sex offenders from "normal" individuals without a history of criminal sexual offenses on the basis of objective personality test data as measured by the MMPI. The sex offender population was defined as "men convicted of some sexual offense, the majority of which occurred with children, and committed to a state hospital for observation, diagnosis, and treatment." The group form of the MMPI was administered to 100 offenders as part of hospital admission procedures and to a control group of 100 male college students. On the basis of an item analysis of the true and false responses to each of the 566 MMPI items, 100 items were determined as separating sex offenders from normals. MMPI items characterizing offenders included responses 
relating to suspiciousness and projections of fear, passive-dependency, feelings of inadequacy, shyness, guilt, depression, conflicting sexual behavior, amoral attitudes, and strong fundamentalist religious values. As a discriminative test, the empirically derived item scale was then cross validated on further sex offender and student groups as well as on hospitalized populations of neurotic and psychotic patients. Results of the cross-validation studies indicated that the item scale was $88 \%$ efficient in differentiating between known sex offenders and normal individuals. However, the scale did not discriminate between sex offenders and hospitalized patients. This latter result led Marsh et a). (1955) to hypothesize that the Sv scale draws upon factors of personality integration, adjustment, or general abnormality and is not effective as a diagnostic tool for the identification of sex offenders.

The hypothesis of Marsh et al. (1955) was confirmed by Peek and Storms (1956) in a validity study of the Sv scale comparing hospitalized sex offenders, neurotics, psychotics, character and personality disordered individuals, and male psychiatric aides. Holz, Harding, and Glassman (1957) ascertained that the Sv scale was unsuccessful in separating male sexual deviates, latent homosexuals, and characterdisordered Army patients from enlisted men without diagnosed psychiatric histories. In addition, Wattron (1958) utilized the Sv scale as a means of differentiating incarcerated sex offenders with a matched group of other felons. Wattron's findings supported the results of Marsh et al. (1955), Peek and Storms, and Holz et al. (1957) in suggesting that the Sv scale provides a measure of "gross psychiatric maladjustment" and is 
of little or no practical value in discriminating sex offenders from hospitalized mental patients or felons in correctional institutions. Cabeen and Coleman (1961) utilized the Sv scale as the principal criterion for determining an "improvement" in deviancy among 120 male sex offenders remanded to a California state maximum security hospital. The majority of offenders had been found guilty of the crime of child sexual molestation. Offenders were administered the MMPI, including the Sv scale, upon admission to the hospital and following one year of incarceration. Original pathological elevations $(T>79)$ occurred on the Sv scale, in addition to primary elevations on clinical scales 4 and 8. Test change results after one year indicated continuing elevations on scales 4 and 8; however, a significant decrease in mean Sv scale scores $(T \leq 63)$ was noted. Cabeen and Coleman attributed the reduction in the Sv scale scores to a definite decrease in sexual deviancy among offenders, in addition to a change in sexual attitudes and outlets, as well as to a heightened sense of defensiveness resulting from ongoing treatment. The conclusion derived by Cabeen and Coleman on the basis of a decrease in Sv scores stands in direct contrast to the hypothesis of Marsh et al. (1955) and confirmed by the validity studies conducted by Peek and Storms (1956), Holz et al. (1957), and Wattron (1958), indicating that the Sv scale provides only a generalized index of psychiatric abnormality and is inadequate as a diagnostic instrument for identifying and assessing sexual deviancy. The failure to cite and critically evaluate the hypothesis presented by Marsh et al. (1955) and the aforementioned validity studies on the Sv scale limits the credibility 
of the results obtained by Cabeen and Coleman regarding the apparent significant "improvement" in deviancy among sexual offenders.

A second experimental scale, the Pedophile scale (Pe), was developed by Toobert, Bartelme, and Jones (1959). Utilizing data from 120 incarcerated male pedophiles--arbitrarily defined as individuals whose sexual object choice was a male or feinale child 12 years old or younger--and a control sample of 160 male prisoners, Toobert et al. (1959) first established mean MMPI profiles for both groups. Both prisoner groups had primary elevations on scale 4. In addition, pedopniles were found to be significantly more distrustful and have effeminate or passive-interest patterns. An item analysis, undertaken in an effort to establish a predictive tool for identifying pedophiles, produced 24 MMPI items that successfully differentiated pedophilas from control samples in cross-validation studies, with the exception of a diagnosed neurotic patient group of Veterans Administration psychiatric referrals. An analysis of the items that significantly separated pedophiles from others indicated that the pedophile is generally sexually dissatisfied, feels inadequate in interpersonal relationships, experiences considerable guilt, and has strong religious beliefs. The two items that most powerfully discriminated pedophiles from others had religious themes: "I go to church almost every week," and "I read in the Bible several times a week." Forty-six percent of the high scorers on the Pe scale (males endorsing 13 or more of the 24 critical Pe scale items) had offended with male children, $20 \%$ of the high scorers had previous criminal convictions for pedophiliac offenses, whereas only $20 \%$ 
had offended with their own child or a blood relative. In comparison with the low scorers, high scoring offenders were found to evidence more overall emotional disturbance, maladjustrnent, anxiety, reality distortion, and social withdrawal. These results led Toobert et al. (1959) to hypothesize that the Pe scale may serve as an adequate assessment scale for measuring neurotic or general maladjustment tendencies among high scoring pedophiles.

Toobert et al. (1959) summarized the results of the establishment of the Pe scale as tending to:

Confirm the clinical impression that the person whose love object has been a child is not always to be viewed as an aggressive and sexually active person but rather that such symptom behavior in chronic form reflects a person who because of a sense of weakness, inadequacy, and low self-regard, not unrelated to severe disruption in his own family unit during childhood, finds a solution for his tensions in the identification with the physically weaker and emotionally less sophisticated child.

It is the object of this study to extend the early work with pedophiles by Toobert et al. (1959) through the development of an MMPI experimental item scale for the specific identification of incest offenders. For the purposes of this study, incest is defined as the sexual mistreatment of a child by the father, by a close male family member, or by a male assuming the parent role (stepfather, mother's boyfriend, etc.) and encompasses all forms of sexual behavior from fondling to intercourse (based on Anderson and Shafer, 1979). In contrast, pedophilia is diagnostically defined as "the act or fantasy of engaging in sexual activity with prepubertal children as a repeatedly 
preferred or exclusive method of achieving sexual excitement" (American Psychiatric Association, 1980, p. 271). This study is based on a model of psychopathology of sexual deviance and seeks to examine the hypothesis that one salient, unique item scale can be empirically constructed on the basis of objective psychometric data, as provided by the MMPI, that typifies the incest offender. A second hypothesis predicts that the majority of MMPI items found to be critical in discriminating incest offenders will be those items most generally associated with the two-point code profile of 48/84 (Graham, 1977). 


\section{CHAPTER II}

\section{METHOD}

\section{SUBJECTS}

The responses of two subject groups were compared in the process of item selection for the original experinental scale construction. Group 1, the criterion group, consisted of a total of 93 fathers and father surrogates (close male family member, stepfather, mother's boyfriend, etc.) found guilty of incest offenses and evaluated for possible inclusion in the Sexual Offenders Program operated by Providence Medical Center, Mental Health Services, Day Treatment Program. Group 1 offenders had a mean age of 38.3 years $(\underline{S D}=7.5)$, with a range of 20 65 years. In most cases, incest offenders were remanded to the Sexual Offenders Program by Court order. Criminal charges of Group 1 offenders included Incest, Child Molestation, Indecent Liberties, Sexual Abuse, Sodomy, and Rape.

Group 2, the control sample, consisted of 37 male college students without a known history of criminal sexual offenses. Deinographic data were unavailable for seven of the control subjects. Mean age of the control group, formulated on the basis of available demographic information, was 28.9 years $(\underline{S D}=5.1)$, with a range of 23-41 years.

In addition, an experimental sample, Group 3, composed of a total of 33 incest fathers and father surrogates, formed a cross-validation population for the evaluation of the MMPI experimental item scale. The 
experimental sample was obtained through the courtesy of a licensed clinical psychologist specializing in the assessment and treatment of sexual offenders and comprised a separate data pool: None of Group 3 MMPI offender data were used in the original item-selection phase of the study. Mean age of the experimental sample was 39.7 years ( $\underline{\text { DD }}=$ 8.8), with a range of 26-59 years. Criminal charges for Group 3 offenders included Incest, Child Molestation, Sexual Abuse, Sodomy, and Rape.

In all cases, strict standards of confidentiality were maintained in order to preserve subject anonymity.

\section{MATERIALS}

Currently available individual short form MMPI data limited to 399 items were obtained from each of the 163 subjects. Offenders in Groups 1 and 3 were administered Form R of the MMPI (Hathaway \& McKinley, 1943) as part of the psychological assessment procedure undertaken prior to the formulation of individual treatment plans. MMPI data from Group 1 offenders were obtained over the period from May 1980 through June 1984. Group 3 offenders underwent assessment during the period June 1981 through September 1984.

Group 2 control subjects completed the MMPI between January 1984 and April 1984. MMPI data on individual control subjects were gathered by another graduate researcher for potential inclusion in a separate study. However, these MMPI data have been used exclusively for the development of the present incest offender scale. 
A discrepancy was found between the MMPI question booklets used by Group 1 and the booklets used by Group 2. Specifically, items 367 through 399 in the booklets used by control subjects differed from the items with corresponding numbers in the test booklets used by Group 1 offenders. The item statements presented to Group 2 were transposed to correspond with the item numbers in the test booklets used by Group 1 offenders before the statistical analyses were performed (see Table IV in the Appendix for the corrected MMPI item lists). This ensured that the responses to the items were correctly matched between groups. However, differences in responses due to the different ordering of the items could not be controlled for; this should be remembered when interpreting the results of this study.

\section{SCALE DEVELOPMENT METHODOLOGY}

The MMPI scale for the identification of incest offenders was developed in accordance with the empirical scale construction procedures formulated by Clopton (1978) and consisted of two phases: (a) item selection, and (b) cross validation. In addition, an estimate of reliability was obtained for the derived experimental item scale.

The item-selection process involved an item analysis comparing the True and False MMPI response frequencies of the offender criterion group, Group 1, with that of Group 2 control subjects. A $2 \times 2$ contingency table (Offender vs. Control subject; True vs. False item response) was constructed for each of the 399 MMPI items, and those items with the largest chi-square values were retained as significantly 
differentiating male incest offenders from male control subjects.

In the cross-validation phase, Group 3 experimental subjects' True and False MMPI item-response frequencies for the critical questions derived in the item-selection process were compared with Group 2 itemresponse frequencies on the same critical questions by means of a chisquare procedure. Again, those items which successfully discriminated offenders from control subjects in the cross-validation process were retained.

A reliability procedure, Kuder-Richardson formula 20, was applied to the experimental scale

$$
\alpha=\frac{k}{k-1}\left(1-\frac{\sum_{i=1}^{k} S_{i}^{2}}{S_{T}^{2}}\right)
$$

where

$K=$ number of items,

$s_{i}^{2}=$ variance of item $i$

$S_{T}{ }^{2}=$ variance of the sum over $K$ items,

Several items which did not successfully discriminate in this reliability procedure were omitted. The remaining MMPI items constituted the Incest offender scale (IC).

An incest offender scale score was defined as the sum of the empirically derived MMPI scale items answered in the "appropriate" direction. In order to maximize the predictive value of the 
experimental scale and to minimize the inclusion of incorrectly classified individuals ("false positives"), a cutting score to differentiate high scorers from low scorers was arbitrarily determined. 


\section{CHAPTER III}

\section{RESULTS}

The descriptive statistical analyses indicated that Group 2 control subjects were significantly younger than both Group 1 and Group 3 offenders, $\underline{F}(2,151)=21.19, \underline{p}<.0001$, and had completed more years of formal education, $\underline{F}(2,151)=30.82, \underline{p}<.0001$. Offenders in Groups 1 and 3 were comparable in age and educational background. No statistically significant differences were found between the three subject groups with respect to marital status at the time of assessment, or in the number of previous marriages experienced by the individuals in each group.

Descriptive data specific to offender Groups 1 and 3 indicated that $93 \%$ of the incest victims offended against were female. Mean number of victims offended against was $1.5(\underline{S D}=1.3)$, and $1.3(\underline{S D}=.5)$ for Groups 1 and 3, respectively. Incest victims of Group 1 offenders had a mean age of 10.6 years $(\underline{S D}=3.7)$. Group 3 victims had a mean age of 9.3 years $(\underline{S D}=3.4)$. Victims offended against by Group 3 males were statistically significantly younger, $\underline{F}(1,183)=4.18, p<.04$. The duration of incestuous contact maintained between offender and victim was comparable for the two offender groups. Duration of abuses ranged from one incestuous contact with one victim to repeated contacts maintained over a period of 13 years with multiple victims. No statistically significant differences were obtained in the type of 
criminal offense charged against offender groups. However, the most frequently charged criminal offense was Sexual Abuse, followed by Sodomy and Rape.

In the original item-selection phase of the experimental scale development, the chi-square tests yielded 19 out of the total 399 MMPI items that significantly differentiated Group 1 offenders from Group 2 control subjects $(p<.001)$. Chi-square tests comparing the itemresponse frequencies of the experimental sample, Group 3, with the itemresponse frequencies of Group 2 on the 19 critical items retained 15 of the original 19 items as significant in discriminating male incest offenders from nonoffenders $(p<.001$; see Table $V$, Appendix, for items omitted in the scale development process). Utilizing ordinary unitweight scoring of the number of experimentally derived items correctly endorsed and an arbitrary cutting score of 5 items endorsed to separate high from low scorers, the 15 -item scale correctly classified $68 \%$ of the criterion offender sample, Group 1, and $76 \%$ of Group 3 experimental subjects when compared to Control Group 2 (Figure 1).

A discriminant analysis applied to the 15-item experimental scale comparing the item responses of Group 1 offenders to Group 2 controls resulted in a $94 \%$ correct classification of male incest offenders, $\underline{x}^{2}(15)=138.79, \underline{p}<.0001$. The coefficients derived from the discriminant analysis were applied to an analysis of Group 2 versus Group 3 item responses, and a 79\% correct classification of incest offenders was obtained. (See Table VI, Appendix, for the discriminant coefficients applied to the 15-item scale.) 
Group 1, Criterion Offenders $(n=93)$

coseses Group 2, Controls ( $n=37$ )

Group 3, Experimental Offenders ( $\underline{n}=33$ )

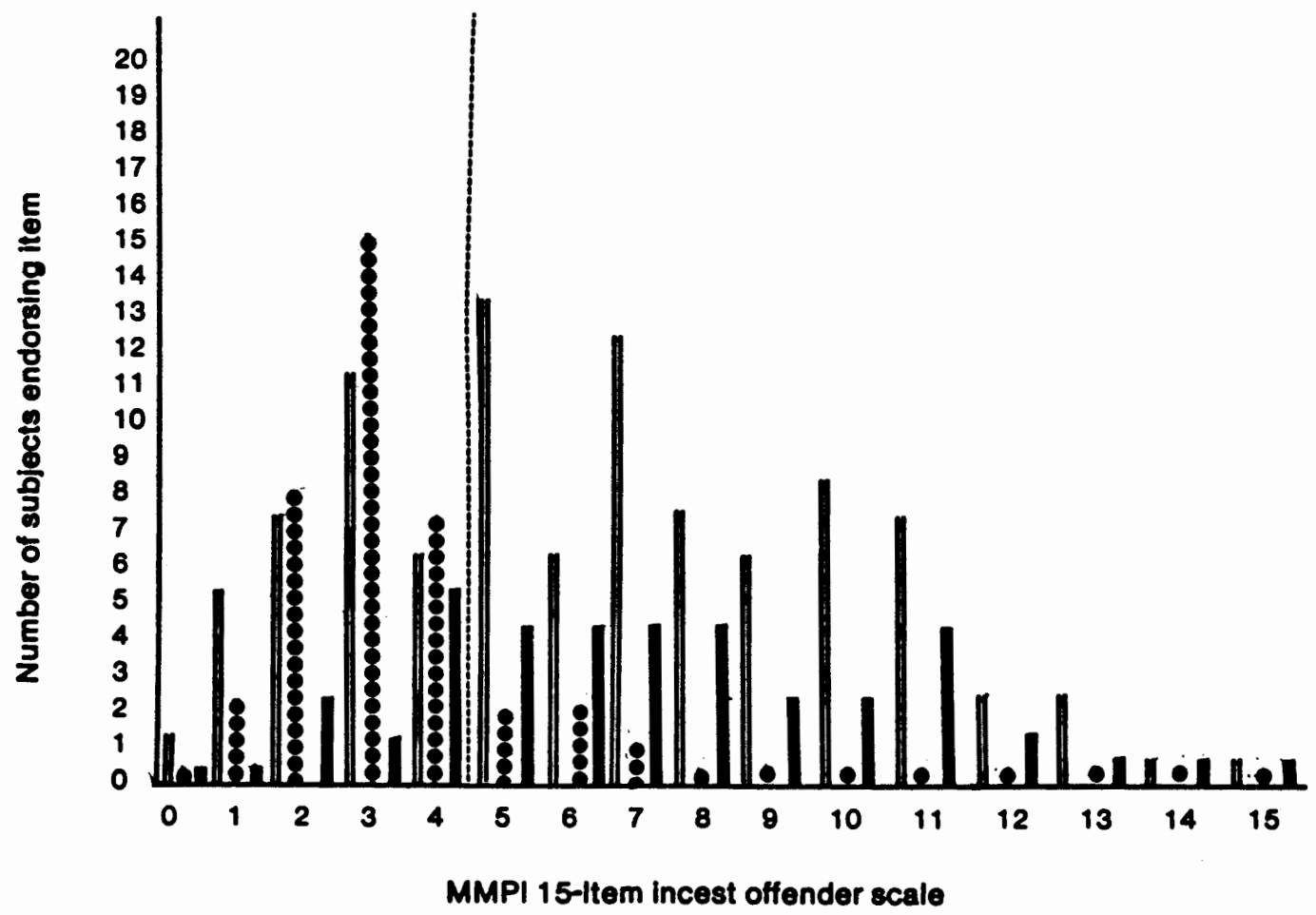

Figure 1. Response rate on the 15-item MMPI experimental incest offender scale with an arbitrary cutting score of 5 . 
Reliability measurement conducted on the 15-item scale employing Kuder-Richardson reliability formula 20, yielded an experimental item scale reliability coefficient of $\alpha=.50, \underline{F}(162,2282)=16.57, P$ $<.0001$. This coefficient indicated limited experimental scale accuracy in separating male incest offenders from nonoffenders and only moderate content homogeneity among the 15 derived MMPI items. On the basis of the Kuder-Richardson reliability measurement, four items were omitted from the 15-item scale due to poor performance in differentiating offender from control subjects (see Table V, Appendix, for items omitted in the scale development process). Reducing the scale from 15 to 11 items increased the experimental item scale reliability from $\alpha=.50$ to $\alpha$ $=.77, \underline{F}(162,1630)=4.89, E<.0001$. A reliability coefficient of $\alpha$ $=.77$ indicated that the experimental scale items measure the same psychological dimension in combined incest offender samples and that the resulting 11-item scale is both homogeneous and valid.

Use of the 11-item scale with an arbitrary score of 4 endorsed items to separate high from low scorers yielded a $72 \%$ correct classification of Group 1 offenders and correctly classified $67 \%$ of Group 3 offenders (Figure 2). Mean percent correct classification of both offender Groups 1 and 3 was $77 \%$ with the 15 - and 11-item scales. However, by omitting four poorly performing items from the 15-item scale, a significant increase in item-scale reliability was obtained. Table I summarizes the percent correct classifications and respective cutting scores of offender and control groups utilizing the original 15item scale and the final 11-item experimental scale. 

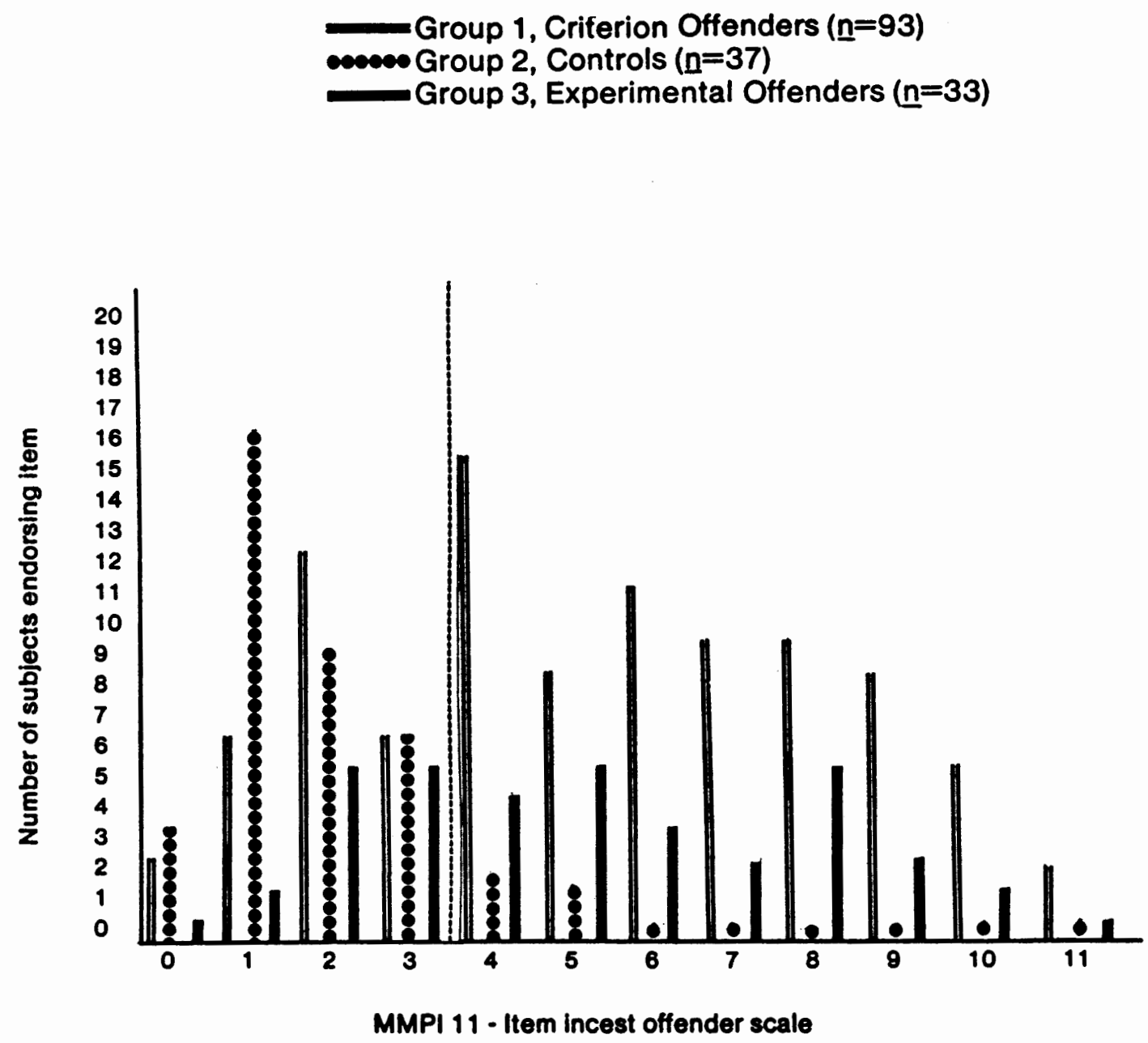

Figure 2. Response rate on the 11-item MMPI experimental incest offender scale with an arbitrary cutting score of 4. 


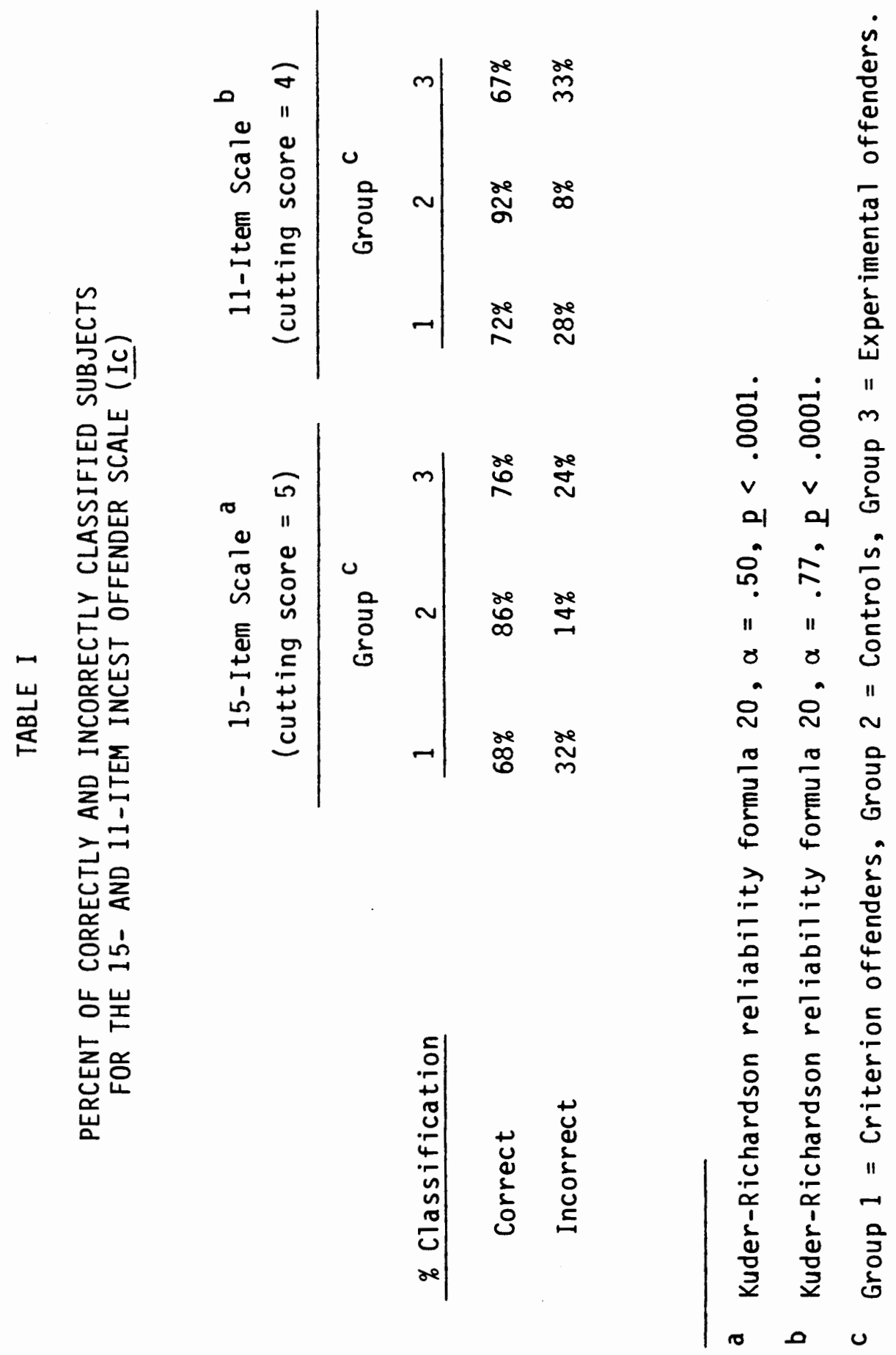


Due to the large number of statistical comparisons performed, a simple mathematical manipulation cited by Clopton (1978) was undertaken in order to determine the possible number of items included in the experimental scale that could have obtained significance entirely as a result of chance fluctuations. The total number of MMPI items administered (399) was multiplied by the level of statistical significance $(.001)$ used for the chi-square test associations. According to this formula, it was determined that less than one item was included in the experimental scale strictly on a chance basis.

The 11-item experimental MMPI scale constituted the Incest offender scale (IC) and is summarized in Table II. This table presents: the number and verbal content of items that constitute the Ic scale; the MMPI clinical scale from which the item is derived; the "appropriate" direction of scoring for the item; the percent of offender, control, and experimental subjects endorsing each item; and chi-square values for each of the critical items.

The Ic scale score was the total number of the experimentally derived MMPI items, out of 11 possible, answered in the appropriate direction (see Table II). In the development of the 11-item scale, a cutting score of 4 endorsed items was used to discriminate high scorers from low scorers. Based on a cutting score of $4,8 \%$ of control subjects were misclassified as offenders ("false positive" identification), whereas a mean of $31 \%$ of the incest offender sample was incorrectly classified as nonoffenders ("false negative" identification). Reducing the cutting score from 4 to 3 on the 11 -item scale resulted in a $24 \%$ 


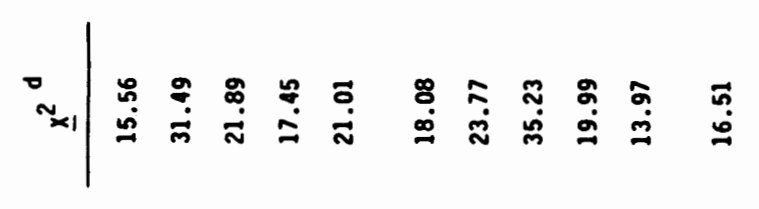

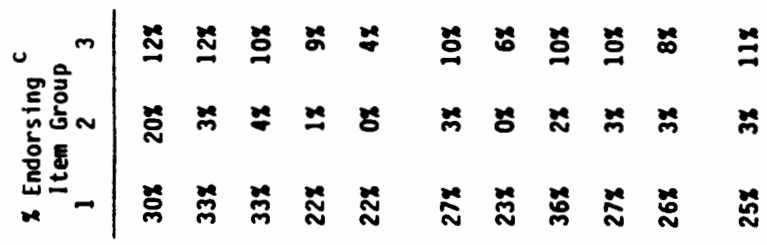

$$
\mid
$$

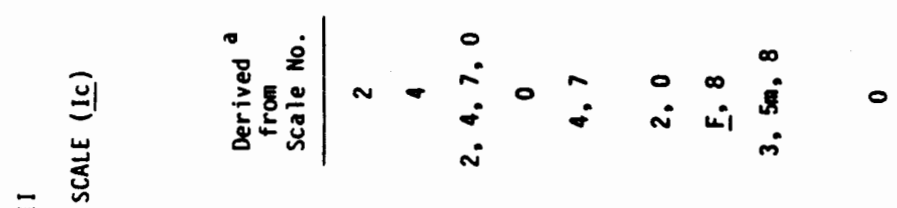

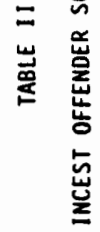

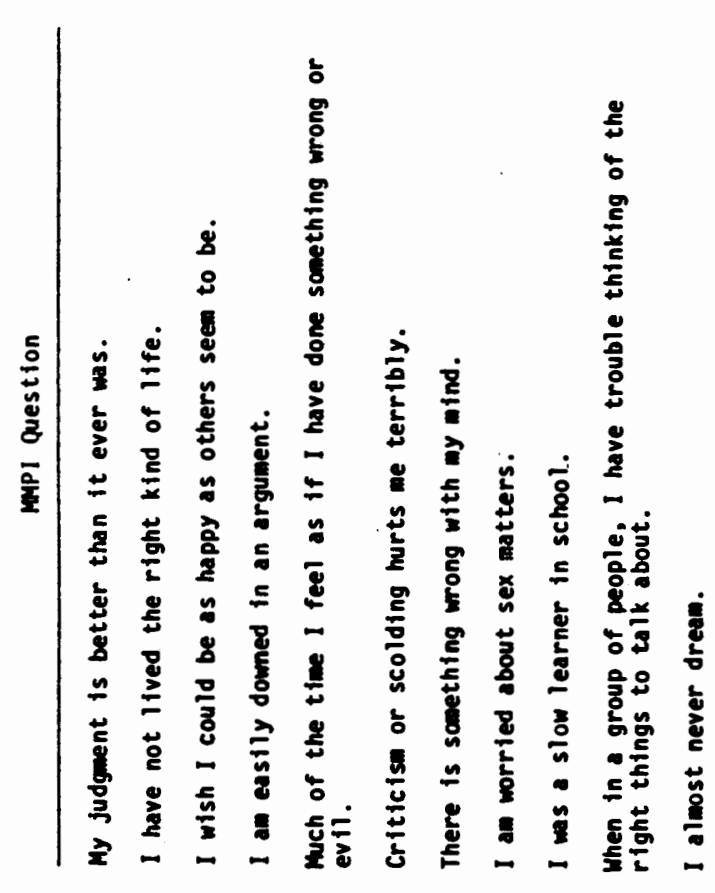

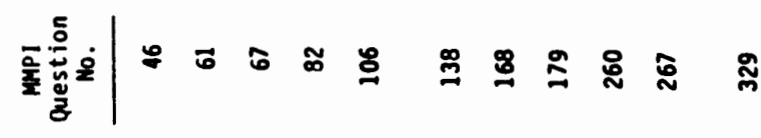

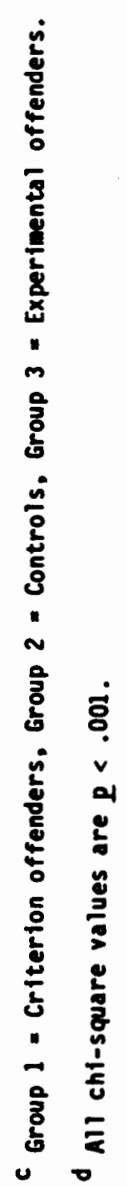


incorrect classification of nonoffenders as offenders, while a mean of $20 \%$ of offenders were incorrectly identified as nonoffenders.

The control sample item responses formed a normal distribution at the low end of the 11-item experimental scale. A bimodal distribution, with scores spread over the entire 11-item scale, was produced by the item endorsements of Groups 1 and 3 (see Figure 2).

Mean MMPI clinical scale scores and profiles for Groups 1, 2, and 3 are presented in Figures 3-5. MMPI clinical scale score data from Group 1 were based on a sample of 66 offenders. Scale score information for 27 offenders was unavailable. An analysis of variance performed on each of 12 MMPI scales, with the exception of the "cannot say" validity scale, indicated that one validity scale and seven clinical scales were statistically significant in differentiating offender from control subjects. Offenders had significant elevations on the validity scale $\underline{F}(\underline{p}<.004)$ and $c l i n i c a l$ scales 1 (Hysteria; $p<.03), 2$ (Depression; $\underline{\mathrm{p}}<.002), 6$ (Paranoia; $\mathrm{p}<.03$ ), and 7 (Psychasthenia; $\mathrm{p}<.001$ ). In particular, offender groups obtained significant elevations on clinical scales 4 (Psychopathic deviate; $p<.0001$ ), 8 (Schizophrenia; $p<.0002$ ), and 0 (Social introversion; $p<.0001$ ), in comparison with Group 2. A discriminant function was conducted on the MMPI clinical T-scale scores for Group 1 versus Group 2. Based on this analysis, a $94 \%$ correct classification of incest offenders was obtained, $\underline{X}(13)=87.59$, $\underline{p}<.0001$. The standardized canonical discriminant function coefficients (see Table VII, Appendix), derived from the MMPI clinical scale score analysis, were applied to the $\underline{K}$-corrected raw scale scores 

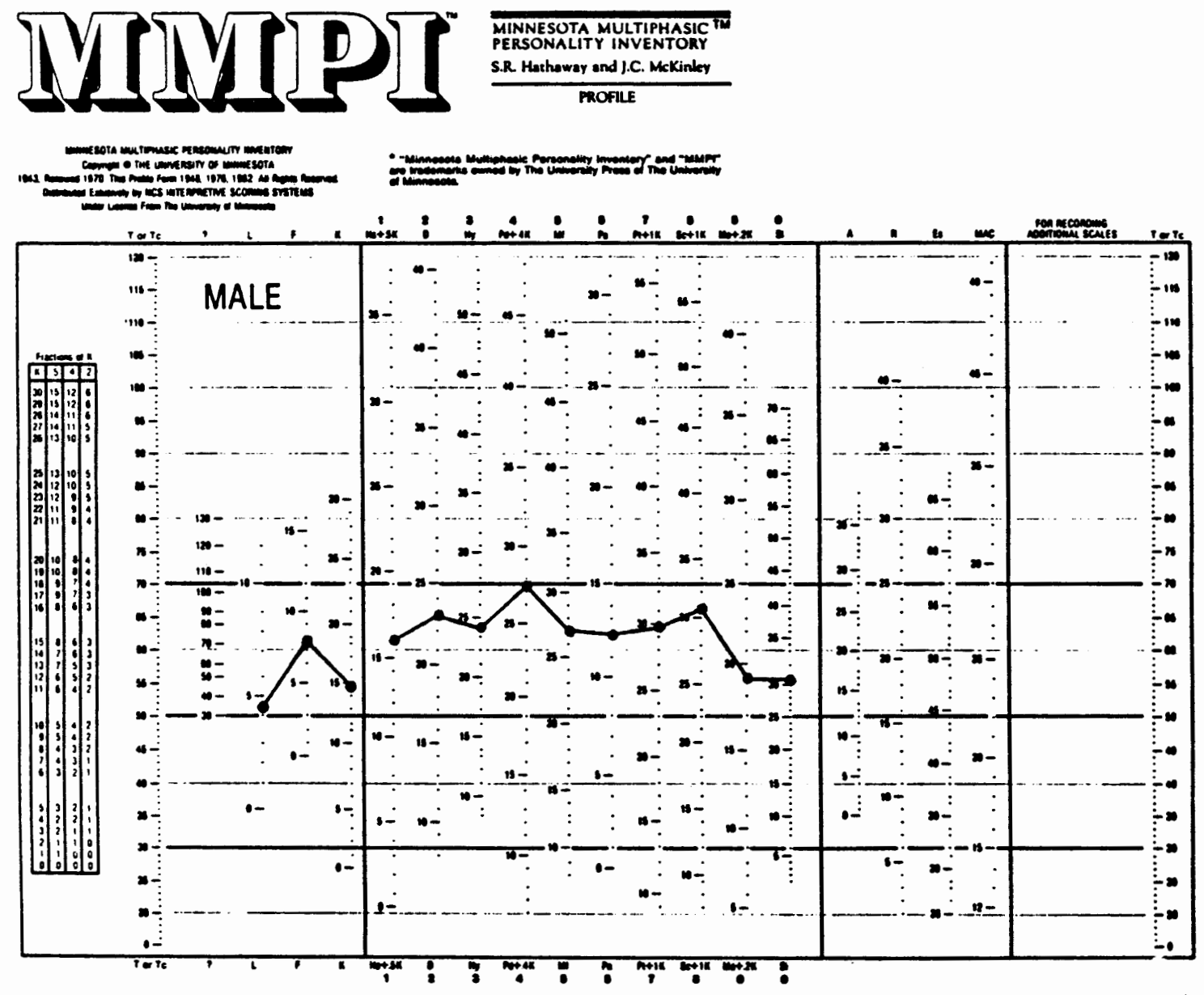

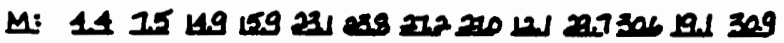

50 2450545.756 .048473 .56 .4764 .39 .1

Figure 3. Group 1, criterion offender sample $(\underline{n}=66)$, means and standard deviations for $\underline{K}$-corrected MMPI scale scores. 


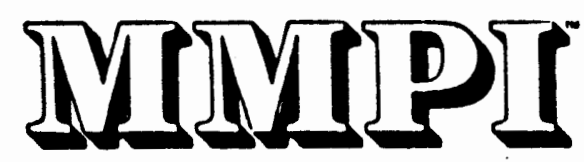

MINNESUTA MULTIPHASICTM

PERSONALITY INVENTURY

S. Henhowor and I.C. MoKinker

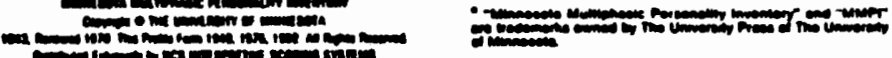

morue

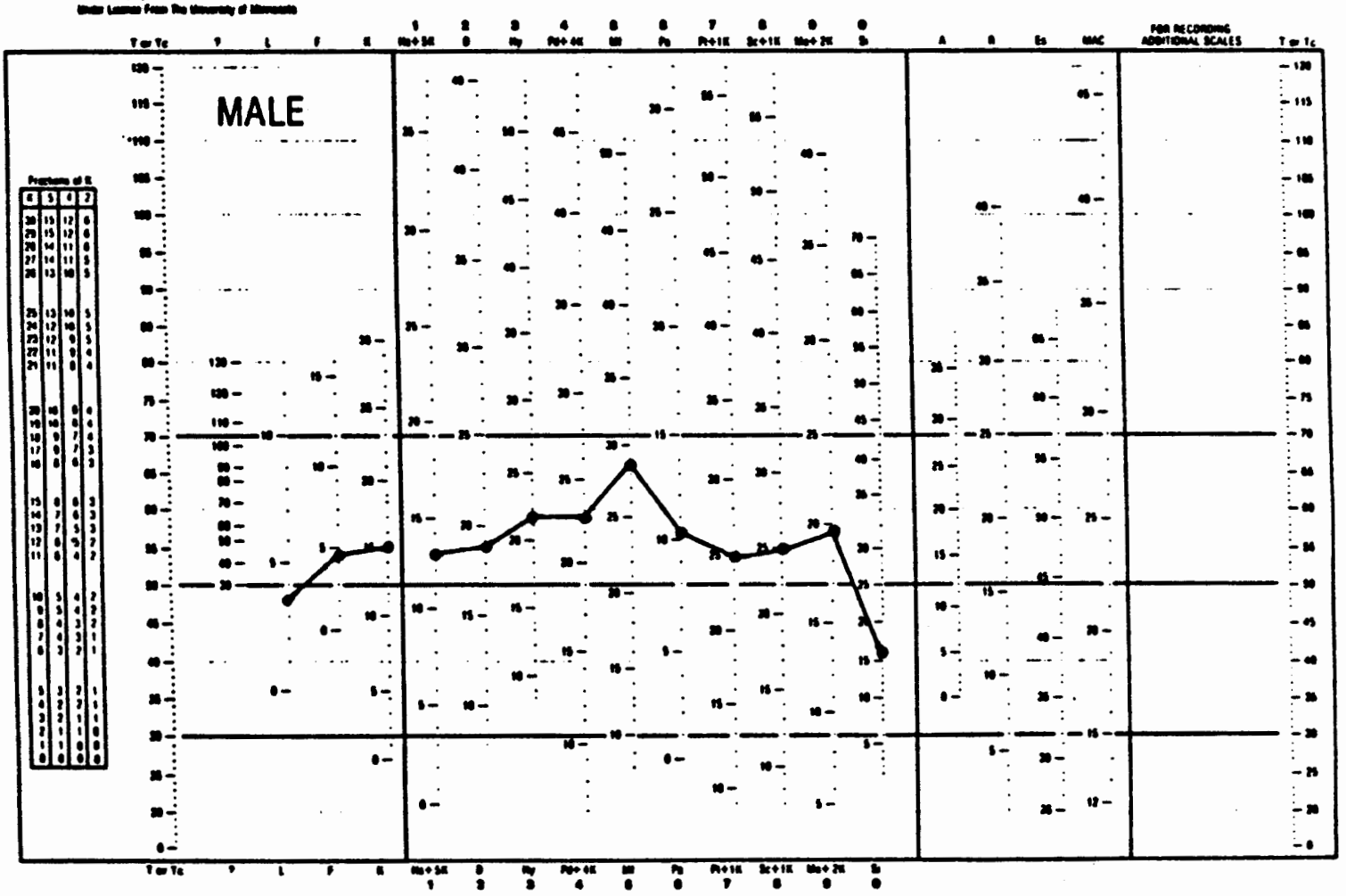

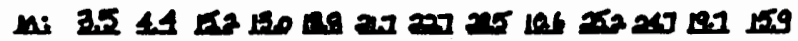

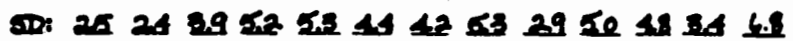

Figure 4. Group 2, control sample ( $\underline{n}=37$ ), means and standard deviations for $\underline{K}$-corrected MMPI scale scores. 

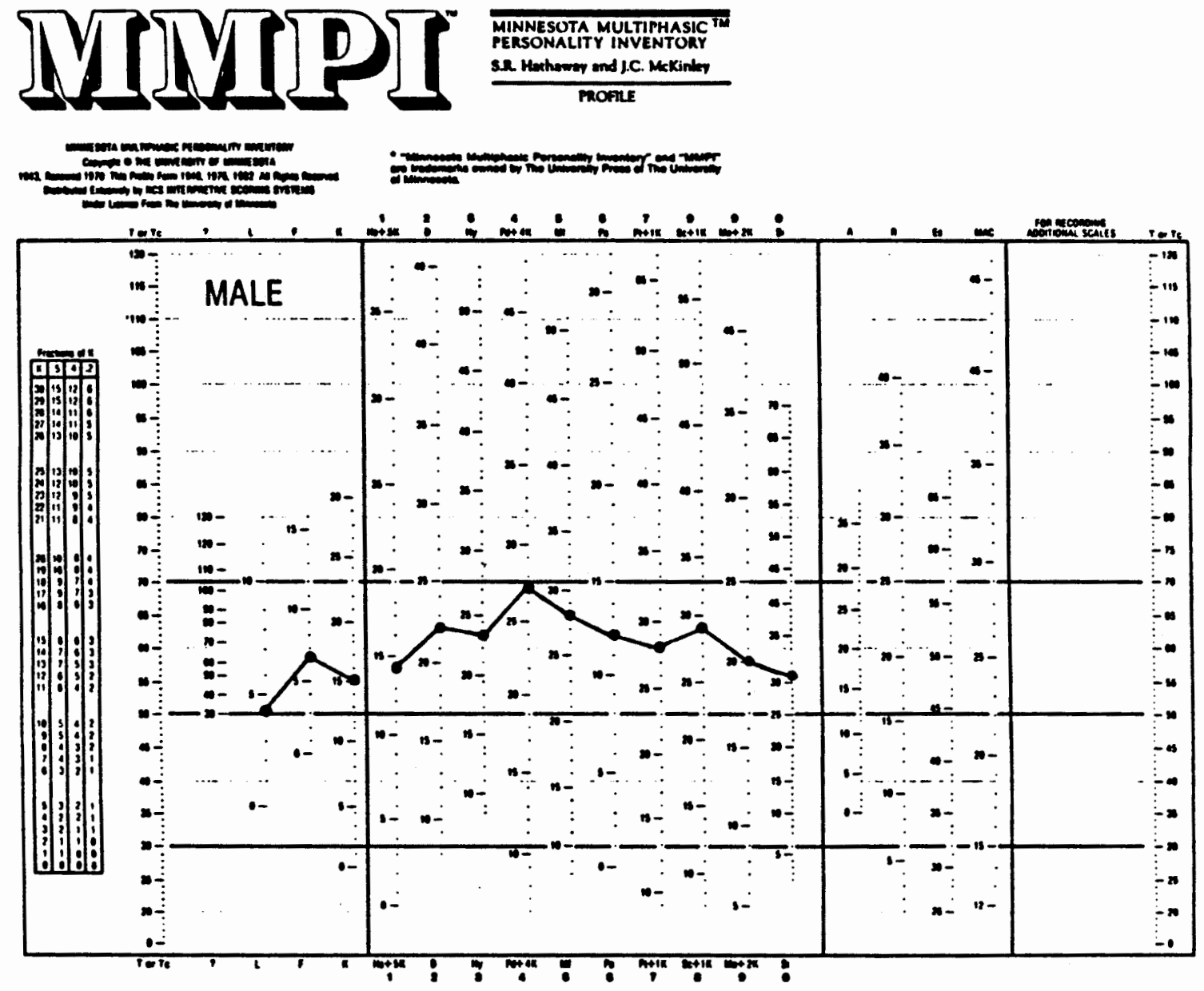

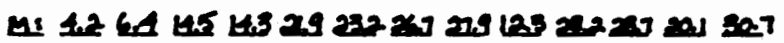

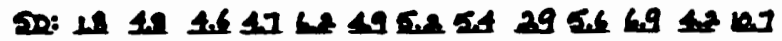

Figure 5. Group 3, experimental offender sample $(\underline{n}=33)$, means and standard deviations for $\underline{K}$-corrected MMPI scale scores. 
of Group 3 incest offenders. Ninety-four percent of Group 3 offenders were correctly classified on the basis of the discriminant function when compared with Group 2. In assessing the discriminant function coefficients, scale 0 (Social introversion) predominated in distinguishing incest offenders from nonoffenders, followed by the validity scale $\underline{K}$, and clinical scales 3 (Hysteria) and 4 (Psychopathic deviate). 


\section{CHAPTER IV}

\section{DISCUSSION}

The results indicate strong support for the original hypothesis that one salient, unique MMPI item scale (IC) can be empirically derived to identify male incest offenders. The derived Ic scale appears to have both high face validity and high content validity. The Ic scale also appears to be reliable in assessing the same psychological dimension in differing incest offender populations.

The majority of Ic MMPI scale items found to be critical in differentiating offender from control subjects were items derived from clinical scales 0,2 , and 4 , thus lending only moderate support to the second hypothesis of this study that the items found to be significant in identifying male incest offenders would be those items most generally associated with the two-point code profile of $48 / 84$. The failure to obtain one modal two-point code profile that successfully discriminates offenders from nonoffenders supports the hypotheses of Anderson et a1. (1979), and Armentrout and Hauer (1978), that no single two-point MMPI code is characteristic of male incest offenders.

Items incorporated in scale 0 represent issues dealing with social introversion, including reserved or timid personality styles, low levels of self-confidence, sensitivity to others, inflexible approaches to problem solving, and patterns of emotional responsiveness. Scale 2 items characterize depressive tendencies, including somatic complaints, 
self-confidence issues, social withdrawal, and avoidance of interpersonal relationships. The items comprising clinical scale 4 assess patterns of sexual acting out, difficulty with the integration of societal values, impulsivity, immaturity, and inability to form personal attachments.

In assessing the derivation of experimental MMPI scales, Dahlstrom and Welsh (1970, p. 338) caution against reliance upon content analys is of derived scale items. Dahlstrom and Welsh maintain that it is difficult to determine what "particular word, phrase or semantic feature of each of the relevant items is responsible for the obtained discriminations." However, an evaluation of the verbal content of the items constituting the Ic MMPI scale shows a consistent degree of homogeneity of content. In general, the 11 individual scale items indicate pervasive feelings of insecurity and social inadequacy among incest offenders. Incestuous males can be characterized as sensitive, introverted, and reserved. The items endorsed by offenders provide evidence of low levels of self-esteem and self-confidence, conspicuous social skill deficits, a concern over sexual issues, and passive personality traits, as well as generalized feelings of frustration and depression. The summary of offender personality attributes derived from the Ic MMPI scale is corroborated through direct clinical experience involving the assessment and treatment of male incest offenders ( $P$. Barbur, personal communication, December 28, 1984; Farrenkopf, 1984). It appears that the pervasive feelings of social isolation endorsed by offenders may extend to their role as partners in intimate 
relationships. Offenders may be unable to enhance emotional ties with their adult partner or to seek satisfactory adult contacts outside of their present relationships. It is hypothesized that the social alienation experienced by offenders may result in marital dysfunctions and may serve as a contributory mechanism in offenders' initiation and maintenance of incestuous contact. This hypothesis supports similar hypotheses proposed by Anderson and Shafer (1979), Langevin et al. (1978), Marsh et al. (1955), Panton (1979), and Toobert et al. (1959).

The depressive tendencies manifested in the IC scale items may be attributed to the offenders' long-standing feelings of social inadequacy, passivity, and inability to establish supportive relationships. Offenders may also have undergone recent family dissolution resulting from the disclosure of the incestuous behavior. In addition, offenders may have been experiencing a reactive depression at the time of the MMPI assessment as a result of their involvement in the judicial process, including mandated compliance with sexual offender evaluation and treatment programs.

Missing among the individual Ic scale items are indicators of guilt or feelings of remorse stemming from inappropriate sexual behavior, feelings that are considered important for the successful treatment of sexual offenders (Providence Medical Center, 1982). Evidence of guilt feelings experienced by offenders has been substantiated in previous MMPI studies conducted by Langevin et a1. (1978), and Marsh et a1. (1955) in an analysis of items comprising the Sv scale, and by Toobert et al. (1959) in the derivation of the Pe scale for the specific identification 
of pedophiles. Also absent in the Ic scale are items related to fundamentalist religious convictions, items that were found to be critical in identifying deviant sexual offenders as assessed by the Sv scale (Marsh et al., 1955), and, in particular, by the Pe scale derived by Toobert et al. (1959). Cavallin (1906) and Marsh et al. (1955) determined, on the basis of MMPI data, that incestuous males used projection among their primary ego defense mechanisms; however, no manifestations of projective identification are incorporated in the Ic scale.

Nine out of the 100 total items of the Sv scale (Marsh et a1., 1955) overlap with the Ic scale. Given the extensive size of the Sv scale, it does not seem surprising that considerable overlapping of items occurs. The MMPI items held in common between the Sv and Ic scales are 46, 61, 67, 106, 138, 168, 179, 260, and 329 (see Table II). Four items of the $24 \mathrm{Pe}$ scale items derived by Toobert et al. (1959) are shared by the Ic experimental scale and include items 67, 106, 179, and 260 (Table II). All of the Pe scale items shared by the Ic scale are also shared by the Sv scale. The two items specific to the Ic scale and not incorporated in either the $\underline{S v}$ or the $\underline{P e}$ scales are items 82 and 267. These items relate directly to feelings of personal and social inadequacy among offenders.

Marsh et al. (1955) and Toobert et al. (1959) each concluded, on the basis of the development of the $\underline{S v}$ and Pe scales, that no discrete MMPI diagnostic categories could be derived that accurately assessed "sexual deviancy." Rather, it was determined that the $\underline{S v}$ and the Pe 
scales provided only generalized measures of psychological "maladjustment" or "abnormality." Given the extensive sharing of items between the $\underline{S v}, \underline{P e}$, and Ic scales, and based on the homogeneous item content analysis of the IC scale, it is hypothesized that it is precisely those qualities of psychological "maladjustment" or "abnormality" that discriminate incest offenders from nonoffenders.

It is apparent that the essential dynamic underlying incestuous behavior derives from characterological disturbances that include pervasive feelings of psychological and social inadequacy. No evidence of neuroses or psychoses are manifested in the Ic scale. Incest does not appear to result from a distinct psychopathology of sexual deviancy. The predictive value of the Ic experimental scale is limited by the control sample used. The actual variance in the Ic item scale obtained for discriminating offenders from nonoffenders is minimized by uncontrolled demographic characteristics of the control population. Demographic data were unavailable for seven of the subjects. Male control subjects were significantly younger and had more years of formal education in comparison with the two offender groups, and thus may have produced an age and educational artifact in the Ic scale development. Based on the educational levels of the nonoffenders, it may be presumed that, as a whole, the control subjects may have higher intellectual capabilities than offenders, and as a result of educational experience, may have developed more sophisticated test-taking strategies. The overall socioeconomic status of the nonoffenders may be higher than that of the offender population. It is further assumed that the level of 
depression endorsed by offenders may be disproportionately magnified as a result of the control subjects' freedom from incarceration. In addition, it may be hypothesized that the nonoffending sample may have greater sexual impulse control; however, an issue of concern in any study of incest abuse involves a "secret" offender factor that cannot be controlled. Reported incidents of incest do not accurately reflect the actual magnitude of its occurrence. As a result, a substantial baserate incest offender population exists which has not been, and may never be, publicly identified. Therefore, incest behavior research involves the probability that any control sample may be contaminated by the possible, though unintentional, inclusion of unacknowledged "secret" offenders.

The strengths of the present study lie in two primary areas: the use of large incest offender samples, and (b) the use of a homogeneous offender population. In contrast to previous MMPI studies that utilized small samples of offenders (i.e. Cavallin, 1966; Kirkland \& Bauer, 1982), the present experimental MMPI scale incorporated large, representative samples for both the item selection and cross-validation phases of the Ic scale. Second, sexual offenders such as pedophiles, rapists, exposers, or child molesters were excluded from the present study. The two offender groups formed a homogeneous sample whose abuses were strictly limited to incestuous offenses. In addition, all of the offenders used for the development of the IC MMPI scale were evaluated for possible inclusion in outpatient sexual offender treatment programs. No offenders were included in the study who were incarcerated in long- 
term sexual rehabilitation programs, or who were incarcerated for criminal offenses unrelated to their incestuous behavior.

Apart from the inherent theoretical interest that one salient MMPI item scale can be empirically derived that identifies male incest offenders, the Ic scale offers practical utility as a psychological screening device for the objective identification of incest offenders, as well as for the assessment of potential incestuous behavior. Any male endorsing four or more of the Ic scale items can be viewed as at risk of being an incest offender. Further clinical evaluation may then be undertaken to confirm or refute this diagnosis.

The MMPI is an established standard clinical assessment instrument, and the small size of the Ic scale allows for its easy integration into the diagnostic evaluation procedure. The Ic scale is easily scored and requires little additional time and no special clinical training for effective use. The clinical value of the Ic scale is enhanced by the increasing professional and public attention being focused on the problem of incest abuse.

The derived Ic MMPI scale has significant future research potential. In an effort to increase the clinical utility of the derived Ic scale, it is recommended that the present study be replicated using matched offender and nonoffender samples, particularly with regard to age and educational status. It is further recommended that more complete demographic data be compiled on offenders regarding prior criminal offenses and possible substance abuse. 


\section{REFERENCES}

American Psychiatric Association. (1980). Diagnostic and statistical manual of mental disorders (3rd ed.). Washington, DC: Author.

Anderson, L. M., \& Shafer, G. (1979). The character-disordered family: A community treatment model for family sexual abuse. American Journal of Orthopsychiatry, 49, 436-445.

Anderson, W. P., Kunce, J. T., \& Rich, B. (1979). Sex offenders:

Three personality types. Journal of Clinical Psychology, 35, 671676.

Armentrout, J. A., \& Hauer, A. L. (1978). MMPIs of rapists of adults, rapists of children, and non-rapist sex offenders. Journal of Clinical Psychology, 54, 330-332.

Bass, E., \& Thornton, L. (Eds.). (1983). I never told anyone: Writings by women survivors of child sexual abuse. New York: Harper \& Row.

Cabeen, C. W., \& Coleman, J. C. (1961). Group therapy with sex offenders: Description and evaluation of group therapy program in an institutional setting. Journal of Clinical Psychology, 17, 122129.

Cavallin, H. (1966). Incestuous fathers: A clinical report. American Journal of Psychiatry, 122, 1132-1138.

Clopton, J. R. (1978). MMPI scale development methodology. Journal of Personality Assessment, 42, 148-151.

Cormier, B. M., Kennedy, M., \& Sangowicz, J. (1962). Psychodynamics of father daughter incest. Canadian Psychiatric Association Journal, 7, 203-217.

Dahlstrom, W. G., \& Welsh, G. S. (1960). An MMPI Handbook--A guide to use in clinical practice and research. Minneapolis: University of Minnesota Press.

DeVine, R. A. (1980). Incest: a review of the literature. Sexual abuse of children: Selected readings (DHHS Publication No. OHDS 78-30161). Washington, DC: U.S. government Printing Office.

Farrenkopf, T. (1984). Assessment and treatment of sexual offenders: Training manual. Unpublished manuscript. 
Freud, S. (1946). Totem and taboo (A. A. Brill, Trans.). New York: Random House. TOriginal work published 1913).

Freud, S. (1949). An outline of psychoanalysis (J. Strachey, Trans.). New York: W. W. Norton. (Original work publ ished 1940).

Graham, J. R. (1977). The MMPI: A practical guide. New York: Oxford University Press.

Harris, M. M. (1984, May 10). In the mind: A husky voice, a girl's lasting nightmare. The Oregonian, p. B7.

Hartman, B. J. (1967). Comparison of selected experimental MMPI profiles of sexual deviates and sociopaths without sexual deviation. Psychological reports, 20, 234.

Hathaway, S. R., \& Mckinley, J. C. (1943). Minnesota multiphasic personality inventory. New York: The Psychological Corporation.

Herman, J., \& Hirschman, L. (1981). Father-daughter incest. Child sexual abuse: Incest, assault, and sexual exploitation (DHHS Publication No. OHDS 81-30166). Washington, DC: U.S. Government Printing Office.

Holz, W. C., Harding, G. F., \& Glassman, S. M. (1957). A note on the clinical validity of the Marsh-Hilliard-Liechti MMPI sexual deviation scale. Journal of Consulting Psychology, 21, 326.

Kempe, R. S., \& Kempe, C. H. (1984). The common secret: Sexual abuse of children and adolescents. New York: W. H. Freeman.

Kirkland, K. D., \& Bauer, C. A. (1982). MMPI traits of incestuous fathers. Journal of Clinical Psychology, 38, 645-649.

Langevin, R., Paitich, D., Freeman, R., Mann, K., \& Handy, L. (1978). Personality characteristics and sexual anomalies in males. Canadian Journal of Behavioral Science, 10, 222-238.

Lester, D. (1972). Incest. The Journal of Sex Research, 8, 263-285.

Lévi-Strauss, C. (1969). The elementary structures of kinship. Boston: Beacon Press.

Lindzey, G. (1967). Some remarks concerning incest, the incest taboo, and psychoanalytic theory. American Psychologist, 22, 1051-1059.

Machotka, P., Pittman, F. S., \& Flomenhaft, K. (1967). Incest as a family affair. Family Process, $6,98-116$. 
Marsh, J. T., Hilliard, J., \& Liechti, R. (1955). A sexual deviation scale for the MMPI. Journal of Consulting Psychology, 19, 55-59.

McCreary, C. P. (1975). Personality profiles of persons convicted of indecent exposure. Journal of Clinical Psychology, 31, 260-262.

National Center on Child Abuse and Neglect. (1980). Sexual abuse of children: Selected readings (DHHS Publication No. OHDS 78-30161). Washington, OC: U.S. Government Printing Office.

National Center on Child Abuse an Neglect. (1981). Child sexual abuse: Incest, assault, and sexual exploitation (DHHS publication No. OHDS 81-30166). Washington, DC: U.S. Government Printing Office.

Panton, J. H. (1958). MMPI profile configurations among crime classification groups. Journal of Clinical Psychology, 14, 305308.

Panton, J. H. (1979). MMPI Profile configurations associated with incestuous and non-incestuous child molesting. Psychological Reports, 45, 335-338.

Peek, R. M., \& Storms, L. H. (1956). Validity of the Marsh-HilliardLiechti MMPI sexual deviation scale in a state hospital population. Journal of Consulting Psychology, 20, 133-136.

Protective Services, Children's Services Division. (1984). Child abuse in Oregon 1981, 1982, and 1983 and 11 year overview statistical report. Salem, OR: Author.

Providence Medical Center. (1982). Day treatment sexual offenders program. Portland, OR: Author.

Quinsey, V. L. (1977). The assessment and treatment of child molesters: A review. Canadian Psychological Review, 18, 204-220.

Rader, C. M. (1977). MMPI profile types of exposers, rapists, and assaulters in a court services population. Journal of Consulting and Clinical Psychology, 45, 61-69.

Raphling, D. L., Carpenter, B. L., \& Davis, A. (1967). Incest--a genealogical study. Archives of General Psychology, 16, 505-511.

Rush, F. (1980). The best kept secret--sexual abuse of children. New York: McGraw-HitT.

Russe11, D. (1984). Sexual exploitation. Beverly Hills, CA: Sage Publications. 
Sarles, R. M. (1975). Incest. Pediatric Clinics of North America, 22, 633-642.

Swenson, W., \& Grimes, B. (1958). Characteristics of sex offenders admitted to a Minnesota state hospital for pre-sentence psychiatric investigation. Psychiatric Quarterly Supplement, 31, 110-123.

Toobert, S., Bartelme, K. F., \& Jones, E. S. (1959). Some factors related to pedophilia. International Journal of Social Psychiatry, 4, 272-279.

Watson, R., Lubenow, G. C., Greenberg, N. F., King, P., \& Junkin, D. (1984, May 14). Sexual abuse--a hidden epidemic. Newsweek, pp. $30-36$.

Wattron, J. B. (1958). Validity of the Marsh-Hilliard-Liechti MMPI sexual deviation scale in a state prison population. Journal of Consulting Psychology, 22, 16.

Weinberg, S. K. (1955). Incest behavior. New York: Citadel. 
APPENDIX 
TABLE III

MMPI SCALE DESCRIPTORS

Scale

No.

1

2

3

4

5

6

7

8

9

0
Scale

Abbreviation

?

느

$\underline{F}$

$\underline{K}$

Hs

D

Hy

Pd

Mf

$\mathrm{Pa}$

Pt

Sc

Ma

$0 \quad$ si
Scale

Name
Hypochondriasis

Depression

Hysteria

Psychopathic deviate

Masculinity-Femininity

Paranoia

Psychasthenia

Schizophrenia

Hypomania

Social introversion 


\section{TABLE IV}

MMPI QUESTION BOOKLET ITEMS USED BY GROUP 1

CRITERION OFFENDERS AND CORRESPONDING

ITEM NUMBER USED BY GROUP 2

CONTROLS

MMPI Question No.

$\begin{array}{cc}\text { Group 1 } & \text { Group 2 } \\ 367 & 371 \\ 368 & 374 \\ 369 & 377 \\ 370 & 383 \\ 371 & 391 \\ 372 & 397 \\ 373 & 398 \\ 374 & 400 \\ 375 & 406 \\ 376 & 411 \\ 377 & 415 \\ 378 & 427 \\ 379 & 436 \\ 380 & 440 \\ 381 & 446 \\ 382 & 449 \\ 383 & 450\end{array}$

MPSPI Question No.

Group $1 \quad$ Group 2

384

451

385

455

386

461

387

462

388

469

383

473

390

479

391

431

392

482

393

487

394

502

395

505

396

521

397

547

393

549

399

564 


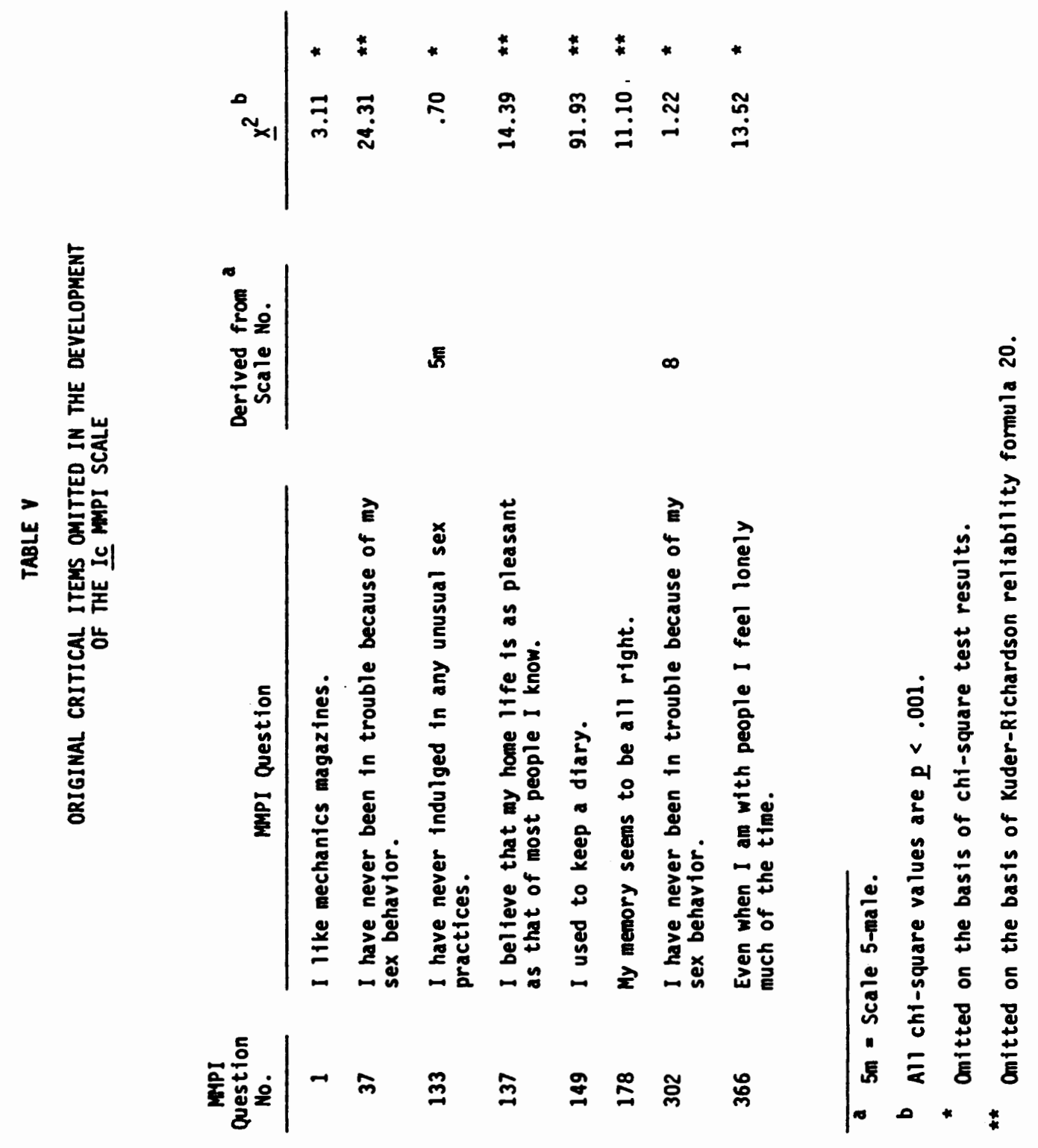




\section{TABLE VI}

STANDARDIZED CANONICAL DISCRIMINANT COEFFICIENTS APPLIED TO THE 15-ITEM MMPI EXPERIMENTAL INCEST

OFFENDER SCALE

Item

1

2

3

4

5

6

7

8

9

10

11

12

13

14

15
Coefficient

$-.33609$

.36315

.29063

.23449

.10239

$-.14478$

.07105

$-.02002$

$-.71431$

.12326

$-.27802$

.17544

.25933

.06095

.27814 


\section{TABLE VII}

STANDARDIZED CANONICAL DISCRIMINANT COEFFICIENTS APPLIED TO MMPI VALIDITY AND CLINICAL SCALE SCORES

\begin{tabular}{|c|c|c|}
\hline \multicolumn{2}{|c|}{ Scale } & Coefficient \\
\hline & $\underline{L}$ & -.14872 \\
\hline & $\underline{F}$ & -.13753 \\
\hline & $\underline{K}$ & .52407 \\
\hline 1 & $\underline{\mathrm{HS}}$ & -.02792 \\
\hline 2 & $\underline{D}$ & -.43597 \\
\hline 3 & Hy & .52087 \\
\hline 4 & $\underline{P d}$ & .39229 \\
\hline 5 & Mf & -.44147 \\
\hline 6 & $\mathrm{~Pa}$ & .02287 \\
\hline 7 & Pt & -.00371 \\
\hline 8 & $\underline{\text { Sc }}$ & -.05572 \\
\hline 9 & Ma & .17286 \\
\hline 0 & $\underline{\mathrm{Si}}$ & 1.40455 \\
\hline
\end{tabular}

